\title{
Una alteración violenta. Sobre ética y filosofía de la religión
}

\author{
Aballay, el hombre sin miedo | Fernando Spiner | 2010 \\ Diego Fonti* \\ Universidad Católica de Córdoba
}

Recibido: 8 de noviembre 2016; aprobado: 18 de febrero 2017

\begin{abstract}
Resumen
En un contexto signado por el retorno de lo religioso, a menudo en sus facetas más cuestionables, vale pensar desde la filosofía de la religión cuál es la estructura que caracteriza esa experiencia, para poder, a partir de allí, esbozar una crítica y recuperar sus posibilidades para una relación responsable y libre con los demás. A partir del cuento y el film "Aballay, el hombre sin miedo”, se propone indagar aquello que Michel de Certeau y Jean Luc Nancy entienden como "esencia" de lo religioso: la posibilidad de sostener una relación con la alteridad incondicional. A diferencia de versiones “domesticadas" de lo religioso, esta relación no excluye la violencia, sino que la incorpora, permitiendo múltiples resignificaciones, tanto destructivas como respetuosas y responsables de la alteridad. Para esta indagación se abordará, en primera instancia, la relación entre deseo del Otro y violencia ética, como pueden verse en la transformación de Aballay. En segundo lugar, se estudiará la subjetividad de quien es "rehén" de esa experiencia de relación con el Otro. Finalmente se abordará la cuestión de la posible universalización de la experiencia, para mostrar la tensión inherente a toda experiencia ética y toda experiencia religiosa, entre la imposible y necesaria tendencia a la universalización.
\end{abstract}

Palabras clave: Aballay | Filosofía de la religión | Ética | Alteridad | Subjetividad | Violencia.

A violent alteration. About ethics and philosophy of religion

\begin{abstract}
In a context characterized by the revival of religions, all too often in their most questionable aspects, it is worthwhile to think from the perspective of philosophy of religion which is the structure characteristic of that experience, in order to both elaborate a critique and recuperate its possibilities for a responsible and free relationship with others. Beginning with the short story and film called "Aballay, the fearless man", I propose to research what Michel de Certeau and Jean Luc Nancy understand as the "essence" of the religious experience: the possibility of holding unto a relationship with unconditional alterity. Unlike the "domesticated" versions of religious experience, this relationship does not exclude violence, but incorporates it, allowing for multiple resignifications, which can be destructive as well as respectful and responsible for that alterity. For this research I will engage first of all the relationship between the desire of the Other and ethical violence, as it can be seen in Aballay's transformation. After that, I will study the subjectivity of whoever is "hostage" of this experience of relationship with the Other. Finally I will engage the issue of the possibility of universalization of this experience, in order to show the tension between the impossibility and need of universalization, which is inherent to every ethical and religious experience.
\end{abstract}

Keywords: Aballay | Philosophy of Religion | Ethics | Alterity | Subjectivity | Violence.

"Si tú me hablas, yo nazco". "Finalmente no hay más que un deber: sostener la relación con lo imposible". (M. de Certeau)

\section{Contexto}

La religión ha vuelto con fuerza. Lo vemos en las noticias sobre el fundamentalismo islámico en oriente me- dio, en las luchas intestinas de musulmanes y cristianos en África, en las masas y pasiones que mueve el Papa, en la injerencia política de los grupos evangélicos, en las espiritualidades new age, y en un largo etcétera. Debido a la dinámica y límites de este trabajo, no ingresaré en la distinción entre religión y religiosidad, fe y creencia, etc., sino que, a riesgo de solapar fenómenos, tomaré estos elementos de modo unificado. Una primera reacción crítica y necesaria ante esta vuelta surge desde esos modos

* diegofonti@gmail.com 
de lenguaje y de comprender al mundo que llamamos filosofía y ciencias sociales. Así, la crítica del sufrimiento, la crueldad, la hipocresía, el ocultamiento, la superstición y tantas consecuencias negativas debidas a la violencia de la comprensión e institucionalización religiosa del mundo es una parte elemental de cualquier proyecto liberador. Al mismo tiempo, parecería que si bien es una enorme tarea, ese tipo de proyectos críticos ya cuenta con suficientes obreros. Por eso es filosóficamente más significativo aproximarse al problema desde otra perspectiva. Como propone Nancy con su deconstrucción, no se tratará aquí de la necesaria acusación a la religión, particularmente al cristianismo, por su relación con las inaceptables consecuencias sociales, ni mucho menos se tratará de su mejora por un aggiornamento o un "retorno" purificador o apologético a algún origen supuesto, sino de la pregunta por cómo se generó, a partir de esta tradición, un modo de relación con lo "inaccesible”, con una alteridad que al mismo tiempo puede hallarse en el mundo y lo desfasa. Se trata también de ver cómo el cristianismo - aunque no de modo excluyente pues puede replicarse este ejercicio en otras tradiciones religiosas "no designa, esencialmente, más que la exigencia de abrir en este mundo una alteridad o una alienación incondicional" (Nancy, 2008: 21). Vista desde la historia de sus efectos, esa exigencia generó mecanismos violentos y se impone la pregunta de si esa violencia se debe a un tipo particular de institucionalización, a decisiones, personajes y eventos históricos, o si no es más bien que hay que suponer un vínculo estructurante, llamémosle "ontológico", que caracteriza toda relación con el Otro, y que sólo puede darse bajo una forma violenta. Claro que esto conllevaría volver a pensar los múltiples sentidos de la violencia y sus manifestaciones; no solo su negatividad sino también su productividad.

Hay diversos accesos a la respuesta. Aquí ensayaré una hipótesis, que afirma que la subjetividad posibilitada por esa relación con el Otro, responde a un tipo de vínculo e incluye necesariamente un modo de respuesta relacionados con una fuerza que podemos denominar violencia. A su vez, esta estructura parece condición imprescindible tanto para comprender el fundamento de las violencias concretas arriba enunciadas, como para pensar también la posibilidad de su superación o un uso constructivo de la misma. Sin esta estructura se vuelven difíciles de comprender las reacciones, discursos y prácticas que demuestran formas de apertura y respuesta a la "convocatoria" de esa alteridad, que pueden denominarse "ética”. Más aún, sin esta condición se vuelve difícil pensar la estructura de la responsabilidad en personajes históricos y aparentemente contradictorios. Schmitt lo plantea de un modo fácil de extrapolar a otros momentos históricos y políticos: "Resulta a duras penas concebible que un filósofo riguroso de la dictadura autoritaria como lo es el diplomático español Donoso Cortés y un rebelde como Padraic Pearse, vinculado a los sindicalistas y entregado con bondad franciscana al pueblo irlandés, fueran ambos devotos católicos" (Schmitt, 2011: 9). Parece enigmático que una matriz religiosa común diera lugar a dictadores e insurgentes, a conservadores y revolucionarios, a devotos y rebeldes. A menos que se permita postular la posibilidad de que esa matriz excede lo simbólico o institucional y alcanza a un tipo de "fundamento" relacional con la alteridad, que por la conmoción que supone permite esa multiplicidad compleja y opuesta de derivados.

Se pueden pensar diversas alternativas ante la hipótesis de un vínculo estrecho entre experiencia religiosa y experiencia ética, que subsiste incluso en una era secular, no debido a un solapamiento de prerrogativas entre estamentos o a la fuerza de la inercia institucional sino por un vínculo inescindible y previo a institucionalizaciones o símbolos. Una de ellas proviene de la teología política de Schmitt $(2009,125 \mathrm{~s})$, que entiende que el secularismo no es sino la continuidad de la estructura religiosa del mundo aunque $\sin$ sus componentes trascendentes o metafísicos, o sea que replica y mantiene la misma jerarquía sin el fundamento que la sostenía previamente. Otra posibilidad, contracara de la anterior, es la que ofrece Blumenberg (2008), quien juzga que hablar de "secularización" es una injusticia, en tanto la modernidad secular no es dependiente de una estructura religiosa a la que se le ha quitado su fundamento metafísico, sino que se sostiene en su propio derecho gracias al auto-empoderamiento del ser humano y su comprensión científica del mundo. Y ya en nuestros días, ante la aparente caída de los discursos "fuertes", hallamos la explicación de Habermas (2011), que aboga por un mundo político neutral en su lenguaje y valoraciones, que sin embargo aproveche de la religión -particularmente judaísmo y cristianismo- su eficacia en generar vínculos de solidaridad y una sensibilidad particular a las intuiciones morales, de la que es incapaz el liberalismo, pero sin indagar una fundamentación de las mismas más allá de la autoreflexión sobre procedimientos discursivos en pos de acuerdos. Y a pesar de sus desacuerdos con Taylor sobre el problema de la fundamentación (Habermas et al., 2011: 61), subyace a ambos una comprensión finalmente utilitaria, casi téc- 
nica, de las posibilidades de la religión en las sociedades modernas. Estas visiones de los usos de lo religioso son ciertamente "útiles", pero como lo sabía Schmitt, la visión pragmático-técnica del mundo, incluida la experiencia religiosa, no sólo elimina lo religioso sino también lo político y toda capacidad de enfrentamiento y superación de lo dado.

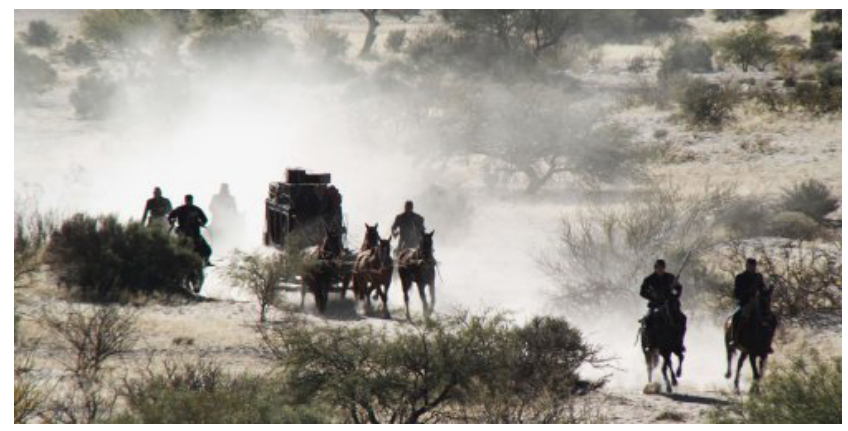

Por eso persiste la pregunta sobre lo religioso y su relación con la ética. La respuesta se vuelve confusa, tanto cuando se intentan separar tajantemente los ámbitos (por ej. sosteniendo que la ética es algo público y la religión pertenece al ámbito individual y privado), como cuando se busca argumentos de una para modificar la otra. Aquí la estrategia será ver cómo ambos son significantes de una relación con el Otro que constituye un modo de respuesta-responsable, el cual a su vez y a posteriori puede tomar diversas configuraciones, lo que constituye su fuerza y la razón de algunas de esas confusiones. En función de este problema, se privilegiará a continuación un abordaje no frontal -con el análisis de conceptos y relaciones históricas- sino oblicuo, tangencial, que permita acceder al corazón del problema a partir de una experiencia estética. Tomando un cuento de Antonio Di Benedetto, Aballay, al que Fernando Spiner llevó a la pantalla, se iniciará un diálogo que permita confrontar la experiencia religiosa siguiendo esa expresión estética, para buscar la matriz violenta de la irrupción de la alteridad como configuradora de una relación ética. En primer lugar se abordará el “evento” por el cual el sujeto se encuentra hablado por el Otro, y con su acción inicia una respuesta y sostiene una relación con eso imposible que desfasa sus capacidades de dar sentido. Esta relación que supera toda relación será denominada ética. A partir de ello se tomarán dos problemas particulares. En primer lugar, el tipo de identidad generada en esa relación con el Otro, y a continuación el problema de la universalización del deber suscitado por ese encuentro.

\section{Deseo de Otro o violencia ética}

La trama se da en un momento de la historia argentina que no se identifica expresamente, aunque algunos indicios pueden ayudar a ubicarlo. ${ }^{1}$ Lo más apropiado es pensar el momento histórico a mediados del s. XIX, pues además de la contextualización de vestimenta, armamento, transporte, etc., en el cuento alguien nombra a Facundo Quiroga "por una acción reciente", aunque hacía "una pila de años" que había muerto (Di Benedetto, 2010: 8). Facundo había sido asesinado en 1835 . También se trata de un ámbito alejado del orden urbano, de la civilidad de la ciudad. Se trata, entonces, del momento de las guerras civiles previo al advenimiento del estado liberal en Argentina, un momento en que todavía las potestades estaban solapadas, entre pequeños estancieros casi feudales, instituciones surgidas de la matriz de un Estado incipiente, y por supuesto la presencia-siempre de frontera y por lo tanto siempre ambivalente- de la Iglesia.

A diferencia del film, que presenta una secuencia cronológica "lógica" -Aballay busca secuaces, persigue la carreta cargada de oro, elimina a los soldados y los viajeros, degüella al padre que intenta distraerlo del escondite de su hijo, encuentra al niño (llamado Julián en el film) y se retira luego de mirarlo, encuentra al cura e inicia su ascetismo-, el cuento empieza con un impacto del lenguaje: alguien oye a alguien. La palabra es una narración sobre algo antiguo, casi mítico, pero que despierta una urgencia ineludible y presente. Algo sucede porque esa palabra recuerda un evento previo. En realidad el evento co-apropiador, al decir de Heidegger (2003: 43), que viene al sujeto, lo asujeta y se apropia de este, y en su libertad el sujeto responde (o no), se muestra en ese momento aunque al mismo tiempo ya ha sucedido. Por eso, ideas como conciencia, proyecto y decisión son segundas, posteriores a la conmoción que en el tiempo descubre algo extra-o para-cronológico. Aballay oye al cura, y le es menos significativo el contenido simbólico del sermón que un detalle, quizás menor, que le llama la atención: la historia de los ascetas que hacían penitencia, en especial los estilitas, y la explicación de que hacían eso como respuesta, "penitencia" a algo sucedido. Se trata de aquellos ascetas que, no contentos con la fugamundi con que la vida monástica resistía a un cristianismo oficial y "aburguesado" - para usar un anacronismo- mediante la vida austera como eremitas o en comunidades de vida sencilla, abandonaban incluso ese mínimo confort y subían a pilares en que pasaban el 
resto de sus vidas. Aballay decide hacer lo mismo pero montado en su caballo.

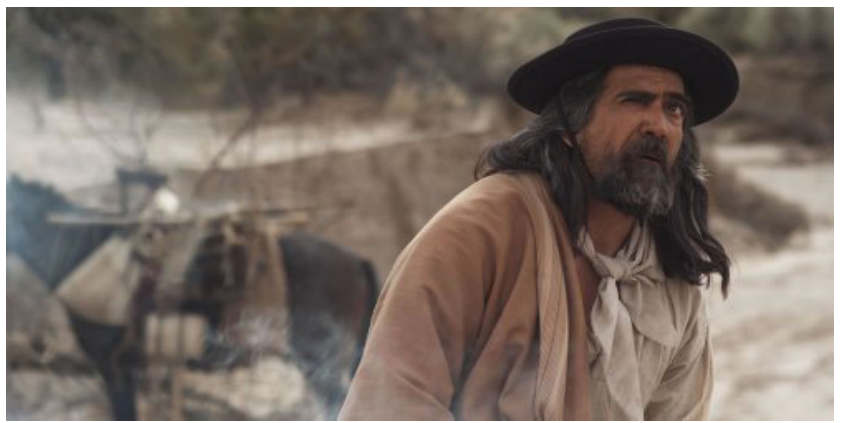

No es la primera vez que estos personajes, en especial el más famoso de ellos, Simeón, son tomados por el arte en general y el cine en particular. En 1965 Buñuel filma un mediometraje (originalmente pensado en versión más larga) llamado "Simón del desierto", que retoma y actualiza la historia reconstruida por Gibbon. Incluso representa el detalle de la prueba de humildad de otros monjes y autoridades eclesiásticas que le ordenan bajar, para ver si no es por orgullo que se mantiene allí. Pero el giro de Di Benedetto/Spiner no es solo la "adaptación” a otra época, lugar y costumbre. También se muestra el rol de la violencia, del rostro y - a partir del uso levinasiano del término- del deseo.

Para Levinas todo empieza con el Otro que viene de la exterioridad y se da bajo la forma del rostro. Pero el rostro no es eso que se ve, y que puede describirse como fenómeno, sino que es un llamado -callado o expreso-al sujeto. A diferencia de la intencionalidad fenomenológica, que aborda, rodea, entiende y conceptualiza aquello que le enfrenta, en el caso del Otro hay un desfasaje de la intencionalidad. Lo que se manifiesta está muy por encima de mis capacidades de donarle sentido o abarcarlo con un concepto. Es importante ver cómo Levinas toma y resignifica un lenguaje vigente en su época, por ejemplo los términos gozo, necesidad, deseo, ${ }^{2}$ y lo resignifica de un modo particular actualizando al mismo tiempo tanto experiencias filosóficas como las "pre-filosóficas". ${ }^{3}$

Una antigua tradición, que el mismo Platón expone y Levinas retoma, vincula esa alteración del deseo con lo infinito del Otro, y a su vez con lo divino: "La posesión por un Dios -el entusiasmo- no es irracional, sino el fin del pensamiento solitario (y que llamaremos más tarde «económico») o interior, comienzo de una verdadera experiencia de lo nuevo y del nóumeno: ya Deseo" (Levinas, 1995: 73). La tensión hacia lo deseable que el deseo inscribe es expuesta por Levinas como algo distinto de la falta que caracteriza a la necesidad.
No es algo que se puede "llenar" y así gozar, sino la instauración de una falta siempre en crecimiento. Levinas propone diversos modos donde ese deseo de Otro se puede identificar: el erotismo, la caricia, la fecundidad, el arte. Pero el "lugar" por excelencia del deseo es la ética, entendida como recepción y respuesta de Otro que se expresa en un rostro: "el contenido primero de la expresión, es esta expresión misma. Abordar el Otro en el discurso, es recibir su expresión en la que desborda en todo momento la idea que implicada un pensamiento. Es pues, recibir del Otro más allá de la capacidad del Yo; lo que significa exactamente: tener la idea de lo infinito. Pero eso significa también ser enseñado. La relación con Otro o el Discurso, es una relación noalérgica, una relación ética, pero ese discurso recibido es una enseñanza. Pero la enseñanza no se convierte en la mayéutica. Viene del exterior y me trae más de lo que contengo (Levinas, 1995: 75).

La exterioridad se da al sujeto de diferentes formas. Mientras el mundo de las cosas se da como "dato" (Levinas, 1995: 207), que permite al "Mismo" -el sujeto en su encierro- acceder a ellas, dominarlas y gozar mediante la satisfacción de sus necesidades, la exterioridad del Otro se reconoce de un modo distinto. Si la necesidad del ser humano permite satisfacción aunque sea momentánea- de ese vacío, el deseo genera un tipo de movimiento imposible de satisfacer, que se ahonda con cada intento de respuesta. Es una conmoción que reclama, y la respuesta al reclamo no hace sino incrementar la demanda. De allí la cercanía insoslayable de la ética, en términos levinasianos, el deseo y la violencia.

La alteridad del Otro no es del orden de los datos, ni tampoco es accesible por analogía o comunidad de género y especie. La relación con el Otro, ética, no es fruto de un acuerdo, una toma de conciencia, un cálculo, o la deconstrucción de cómo históricamente se establecieron vínculos e instituciones. Todas estas tareas, siempre necesarias, corren el riesgo de ser meras expansiones del "Mismo", carentes de reconocimiento del Otro. ¿Cuándo reconoce Aballay al Otro? El degüello del padre del niño lo hizo desde atrás, en cambio vio luego los aterrorizados ojos, calló y no lo pudo olvidar. ¿Qué decía el rostro del niño, que permaneció callado? Entre Otro y yo hay una "diferencia absoluta" que "sólo se instaura por el lenguaje” (Levinas, 1995: 208). Pero esa palabra no es fundamentalmente tematización sino alocución, recepción del Otro y habla propia. Levinas afirma repetidamente que yo reconozco el mandato del otro, 
fundamentalmente no matar, al responder yo mismo. A diferencia del "dejar ser" heideggeriano, hay una "solicitación" que demanda respuesta. Lejos de ser una amable invitación, la palabra del otro "pone pronto en tela de juicio el sentido que doy a mi interlocutor", "anuncia la inviolabilidad ética del otro y, sin ningún resabio 'numinoso' su 'santidad'" (Levinas, 1995, 208). Se ha dado un encuentro con algo absoluto, infinito, que constituye al sujeto sólo si el sujeto puede de alguna manera encasillarlo en un dicho, en alguna estructura simbólica que al mismo tiempo posibilita y traiciona la relación con eso absoluto. ${ }^{4}$ Puede uno preguntarse si la "palabra" del Otro que Levinas "oye", el "no matarás", realmente es la palabra o si no es ella misma un modo de identificar, simbolizar o entificar moralmente al vacío del mandato, y de darle a partir de esa simbolización un sentido englobante al mundo y a sí mismo. Uno puede preguntarse si no es su propia tradición monoteísta la que recurre a ese mandamiento como una traslación, metáfora, que opera un encasillamiento de ese choque originario con toda su violencia y al mismo tiempo lo vuelve sostenible y viable.

Levinas llama "Infinito" a la idea que nace en el sujeto que encuentra al Otro. El Otro es infinito en tanto ningún concepto abarca la trascendencia de su exterioridad. Pero esta descripción fenoménica incluye también una dimensión ética, pues esa exterioridad viene cargada de exigencias que Levinas interpreta bíblicamente: No matar. "La faz positiva de la estructura formal -tener la idea de lo Infinito- equivale en lo concreto al discurso que se precisa como relación ética. Reservamos a la relación entre el ser mundano y el ser trascendente que no lleva a ninguna comunidad del concepto ni a ninguna totalidad -relación sin relación- el término de religión. (...) La religión, en la que la relación subsiste entre el Mismo y el Otro a pesar de la imposibilidad del Todo -la idea de lo Infinito- es la estructura última" (Levinas, 1995: 103).

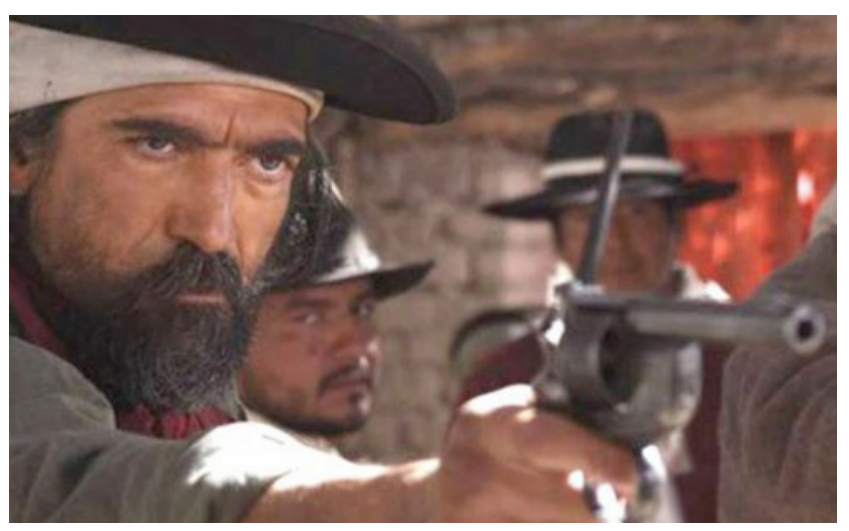

Aballay toma características religiosas, como un "santo". Comienza a responder a quienes acuden a él o reconoce menesterosos de él. Habla y al hablar reconoce su deber. Se da "en el discurso una relación no alérgica con la alteridad", llega "a percibir allí el Deseo, donde el poder, por esencia asesino del Otro, llega a ser, frente al Otro y 'contra todo buen sentido', imposibilidad del asesinato, consideración del Otro o justicia" (Levinas, 1995: 71). El Otro altera al sujeto por su manifestación. Toda violencia con que el sujeto intente responder, por ejemplo definiéndolo, convirtiendo al Otro en un concepto, reduciéndolo a la ontología, identificándolo por vía analógica, sometiéndolo a normas o instituciones, siempre fracasa, porque el Otro se manifiesta finalmente en otro orden. Deseo y mandato no son para Levinas sino modos de expresar cómo el sujeto recibe lo que el Otro manifiesta. Toda la ética de Levinas se esfuerza por exponer, en un contexto histórico que evidencia la máxima violencia posible-guerra y exterminio- una relación que no es violenta sino ética y responsable respecto del otro. Pero esto no impide pensar el término "violencia" como significante precisamente de la experiencia originaria del sujeto: "La violencia que consiste para un espíritu en recibir un ser que le es inadecuado" (Levinas, 1995: 51). En Levinas no se trata sólo de rechazar la violencia "óntica" -crueldad, sevicia, asesinato, exterminio- sino de pensar cómo la filosofía occidental del ser significó un modo de violencia respecto de los otros, y que esa ontología no permitía reconocer y recibir aquello más allá del ser: el Otro (Levinas, 1995: 53). Al mismo tiempo, que Levinas sostiene que la relación con el Otro "no violenta el yo" al modo de una violencia cualquiera, sucede que esa relación "le está impuesta más allá de toda violencia, por una violencia que lo cuestiona totalmente" (Levinas, 1995: 71, cf. 75). Así la ética no es sino sostener la "relación" con esa alteridad que altera al sujeto.

\section{El sujeto-rehén}

Aballay deviene santo. El encuentro/mandato con el Otro reconfigura su vida. No toma como residencia una columna, como los estilitas, sino su caballo. La gente lo ve como un ser capaz de curar o defender. ¿Debe hacer eso? ¿De qué orden es ese deber? ¿Quién le manda? No es casual que muchas lecturas hayan entendido la modernidad como liberación y autonomía respecto de mandatos impuestos, heteronómicos, y por ende 
consideran toda influencia de ese tipo una credulidad, superchería, o simple acomodamiento a imposiciones pragmáticas de supervivencia socialmente viable. Así, Judith Butler indaga, siguiendo la crítica de la violencia de Benjamin y en particular la crítica de la violencia ética en Adorno, el vínculo entre ética y violencia. Ambos son analistas finos de la relación de violencia legal, violencia institucional y la violencia de cualquier proyecto de universalización (Butler, 2005). Pero al mismo tiempo ve algo notable: la noción de "mandamiento" en Benjamin es el modo en que lo "divino" permite resistir a todas las demás imposiciones legales o políticas (Butler, 2006: 205). La alteridad absoluta permite mantener a raya sus supuestos Ersatz, los reemplazos, fetiches o ídolos que pretenden tomar su lugar.

Aballay se vuelve, en términos levinasianos, "rehén" del Otro (Levinas, 1987: 60, 180, 187, 198). No es la ética una acción de un sujeto con "cualidades morales", sino una pasividad, una vuelta a sí-imposible pues pasa por la desviación del Otro. Esa "condición de rehén" de un llamado de Otro -que por supuesto se puede también rechazar, igual que una herencia, pero cuya alocución es imposible no recibir- es una "acusación absoluta", anterior a la libertad y a la decisión, que al mismo tiempo la constituye. Su identidad no está ya dada en su renombre, sus acciones, su voluntad, o sea en todo aquello que le permita identificarse a sí mismo en el campo de sus potencialidades, sino en el modo como asume una deuda impagable. Su identidad es la "no identidad" de la "elección de responsabilidad" del Otro (Casper, 2008: 91). No es casual que en Levinas aparezca la noción de "substitución" (Levinas, 1987: 163), con una carga sacrificial que al mismo tiempo asume y rechaza. La asimetría del Otro que convoca desgarra la interioridad del sujeto. Como rehén del Otro ya ha tomado el lugar de otros. Su identidad es esa posición y esa respuesta.

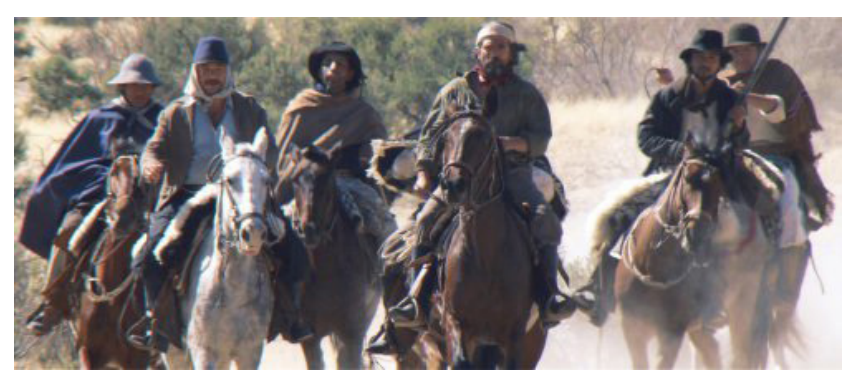

Levinas rechaza del cristianismo no solamente la afirmación de la filiación divina de Jesús, sino algo que en algún sentido fue más influyente: la noción de reemplazo o pago por todos. La economía de la salvación, no muy distinta de otras economías sobre todo a partir de la interpretación de San Anselmo, aúna dos criterios: lo infinito de la deuda y la necesidad de preservación. Por un lado, Anselmo responde a la pregunta Cur Deus homo diciendo que todo pecado contra Dios es infinito, y por tanto sólo un ser infinito (Dios mismo) podría "pagar" esa deuda. Por otro lado, lo sabemos, "conviene que muera uno solo por el pueblo y no perezca toda la nación” (Jn 11: 50). A pesar del uso de términos como sustitución o kenosis, tan ligados a la tradición sacrificial, particularmente cristiana, Levinas intenta desmarcarse de ella, en tanto no hay voluntarismo en la decisión (la recepción del Otro se hace previo a todo ejercicio de libertad), ni hay redención de una vez por todas, ni nadie en especial sino todos deben asumir esa responsabilidad. Más aún, la idea de "sufrimiento inútil" debe ser tenida en cuenta, ya que todo sufrimiento "útil" convertiría al mal en algo aceptable (Levinas, 1993: 125). Una visión así homologaría lo sacrificial al "homo sacer", ese ser divino y repudiable, en todo caso fuera de norma. La hipótesis antropológico-sociológica de Girard (1993) aduce que el inicio de la concordia se debe a la proyección y extrapolación de la negatividad y el conflicto sobre un portador, cuyo sacrificio habilita la vida en común. La hipótesis funcionalista de Girard sobre lo religioso como estructura de reemplazo esencial para posibilitar la constitución de la humanidad, no le impide dar un paso más, casi deontológico: al estar ya consumada la sustitución es inaceptable repetirla. Se la puede recordar simbólicamente, pero ya no se justifica el paso al acto del sacrificio. De este modo, la "violencia" que el Otro ejerce, cuya conmoción Levinas reconoce, no es domesticada sino puesta en un orden de tensión inacabable. Por eso finalmente, y a pesar de todas sus advertencias, Levinas sigue siendo tributario de toda esa estructura occidental (aunque no solo occidental), que entiende que la fuerza que opera el Otro sobre el sujeto impone un tipo de respuesta que configura su identidad. Pero también que esa respuesta es siempre imprescindible y fallida, porque toda concreción definitiva, todo intento de afirmar que el infinito ha sido satisfecho, sería una perversión de la ética y de la responsabilidad respecto del infinito. Esto lleva necesariamente a la pregunta por el tipo de afirmación "universal” que la ética aduce.

\section{El universal: necesidad e imposibilidad}

Universalizar es el movimiento más profundo de Occidente. Su ciencia, su derecho, su moral, estuvieron 
siempre movidas por la necesidad de avanzar con una estructura universalmente aceptada. Esta fue la razón fundamental de toda crítica de las violencias éticas, religiosas, políticas que fueron instituidas. De allí una reacción casi inmediata contra la universalidad. Por otra parte, rechazar la universalidad acabaría, paradojalmente, en una posición conservadora, pues la idea del individuo que se da a sí la ley y no debe rendir cuenta a Otro porta la antigua disposición de los señores griegos. Pero asumir la universalidad sin más, también. ¿Cómo responder al Otro? ¿Deben todos devenir Aballay? ¿Qué tipo de universalidad significa el "No matarás”? ¿Acaso el joven Julián, al enfrentar finalmente a Aballay y asestarle el golpe no está haciendo justicia? Cuando se piensa en ética, inmediatamente dos tradiciones se enfrentan: la prudencial y la deontológica, es decir, la que piensa qué hacer a partir de algún tipo de razonamiento situado y aquella que lo hace desde la formulación de un deber. Pero pensar la ética como relación alterada con y por el Otro impone una nueva visión de lo que es. No significa eliminar la norma, sino situarla en otro plano.

Anotábamos antes que Buñuel toma de la historia del Estagirita el momento en que las autoridades quieren comprobar su humildad y le mandan bajar, mientras que Aballay no responde a las autoridades. Y sin embargo, síse da en Aballay el parangón: baja de su lugar de penitencia, no cuando lo manda la autoridad, sino cuando el joven Julián lo enfrenta y Aballay, que no quiere matarle, se defiende con una caña y en un movimiento brusco ésta se le clava en la boca. "Desmonta a dar socorro, y llega hasta el vencido, pero lo bloquea su ley: no bajar al suelo, y lo ha hecho. Angustiado, levanta la mirada para consultar" (Di Benedetto, 2010: 40), y en ese momento de hesitación el joven lo apuñala. "Por causa de fuerza mayor ha sido" (Di Benedetto, 2010: 41), se excusa ante su ley, y muere.

Si el Otro rompió el solipsismo de la conciencia y su dominio propio y del mundo, también condujo así al sujeto a un deseo de justicia. La justicia busca al mismo tiempo responder a esa tensión hacia el Otro, pero al mismo tiempo pensar los mecanismos sociales para garantizarla. Así, la justicia busca responder al "tercero", o sea a todo-Otro, y esto lo hace mediante el cálculo de justicia, la institución, la sociedad (Levinas, 1987: 241). De allí su posibilidad de construcción y violencia, su necesidad y su imposible realización. De allí también que Levinas recupere una imprescindible pieza para la ética: el escepticismo. Todo proyecto testimonia al Otro, pero si pretende convertirse en el modo final de respuesta conduce a una violencia superior, que pretende agotar la respuesta sin resto. Por ello, confrontar el Decir con lo Dicho, el impulso a responder al y del Otro, permite una distancia que no se cierra. El lenguaje generó la respuesta, pero también "el lenguaje es ya escepticismo" (Levinas 1987, 250) porque sabe de la necesidad, falibilidad y finitud de toda palabra devuelta a la alteración original. El Otro se muestra así imprescindible para el reconocimiento de sí y de todo otro. Al mismo tiempo el Otro excede cualquier figura concreta. Nadie es el Otro. Y sin embargo no hay nadie sin el Otro.

\section{Referencias}

Blumenberg, H. (2008) La legitimación de la edad moderna, Pre-Textos, Valencia.

Casper, B. (2008) Pensar de cara a otro. Elementos del pensamiento de Emmanuel Levinas, EDUCC, Córdoba.

Butler, J. (2006) “Critique, Coercion, and Sacred Life in Benjamin’s 凶Critique of Violence区”, en H. De Vries y L. E. Sullivan, Political Theologies. Public Religions in a Post-Secular World, Fordham University Press, New York.

Butler, J. (2005) Dar cuenta de sí mismo. Violencia ética y responsabilidad, Amorrortu, Buenos Aires.

de Certeau, M.; Cifalli, M. (2002) “Entretien: Mystique et Psychanalyse”, Espaces Temps 80-81, pp. 156-175.

Di Benedetto, A. (2010) Aballay, Adriana Hidalgo, Buenos Aires. Gibbon, E. (1781) Decline and Fall of the Roman Empire, Vol. 3 (disp. en http://www.sacred-texts.com/cla/gib..., consultado el 2/11/2016)

Girard, R. (1993) La violencia y lo sagrado, Anagrama, Barcelona.

Habermas, J.; Taylor, Ch., Butler, J.; West, C. (2011) El poder de la religión en la esfera pública, Trotta, Madrid.

Heidegger, M. (2003) Aportes a la filosofía: acerca del evento, Almagesto/Biblos, Buenos Aires.

Levinas, E.; Sudar, P. (1979) “¿La filosofía, amor a la sabiduría o sabiduría del amor?”, Teología: Revista de la Facultad de Teología de la Pontificia Universidad Católica Argentina, 33, 63-70.

Levinas, E. (1982) Éthique et Infini, Fayard, Paris.

Levinas, E. (1987) De otro modo que ser o más allá de la esencia, Sígueme, Salamanca. 
Levinas, E. (1993) Entre nosotros. Ensayos para pensar en otro, Pretextos, Valencia.

Levinas, E. (1995) Totalidad e Infinito. Ensayo sobre la exterioridad, Sígueme, Salamanca.

Nancy, J.-L. (2008) La declosión. (Deconstrucción del cristianismo, 1), La Cebra, Buenos Aires.

Schmitt, C. (2009) Teología política, Trotta, Madrid.

Schmitt, C. (2011) Catolicismo romano y forma política, Tecnos, Madrid.

1 Y otros indicios engañan, por ej. en la película se canta la Marcha de San Lorenzo, que fue compuesta los primeros años del s. XX.

2 Vale recordar que la obra magna de Levinas, Totalidad e Infinito, data de 1961, aunque recoge ideas desarrolladas desde la segunda mitad de la década de 1940.

3 Para Levinas $(1979,67 ; 1982: 19)$ toda la filosofía reposa sobre experiencias pre-filosóficas. Entre ellas se encuentran no sólo las experiencias de la infancia -Levinas habla de su judaísmo y de su encuentro con los grandes novelistas, particularmente rusos- sino también eventos que acontecieron luego, incluso después de iniciar su tarea filosófica, que necesariamente debieron irrumpir en su filosofía. En el caso de Levinas aparece en primerísimo lugar la guerra y la Shoah, pero se puede extender esta idea a otras experiencias que hayan marcado a quien las tuvo y le demanden su exposición filosófica.

4 Vale recordar que en De otro modo que ser, Levinas (1987: 83) distingue lo "Dicho” (leyes, instituciones, políticas y respuestas concretas, siempre cronológicamente fijadas y por tanto sometidas al tiempo y superables) del "Decir", donde se da una relación diacrónica e imposible de responsabilidad que busca responder a algo infinito y que excede toda fijación. Es una “obsesión”, anterior a toda decisión libre y cálculo de proporción. Y de modo particularmente sorprendente, en una época en que la filosofía se reduce a planteos científicos o técnicos, para Levinas Decir y deseo se vinculan con la antigua tarea filosófica de buscar la sabiduría (Levinas, 1987: 231ss). 